\title{
Belphégor
}

Littérature populaire et culture médiatique

18-1 | 2020

Regards croisés sur la culture médiatique européenne

\section{Regards croisés sur la culture médiatique européenne}

\section{Kálai Sándor}

\section{Q OpenEdition}

1 Journals

\section{Electronic version}

URL: https://journals.openedition.org/belphegor/2155

DOI: $10.4000 /$ belphegor.2155

ISSN: 1499-7185

Publisher

LPCM

\section{Electronic reference}

Kálai Sándor, "Regards croisés sur la culture médiatique européenne ", Belphégor [Online], 18-1 | 2020, Online since 07 February 2020, connection on 30 June 2021. URL: http://journals.openedition.org/ belphegor/2155 ; DOI: https://doi.org/10.4000/belphegor.2155

This text was automatically generated on 30 June 2021.

\section{(c) (i) (9)}

Belphégor est mis à disposition selon les termes de la Licence Creative Commons Attribution - Pas d'Utilisation Commerciale - Pas de Modification 4.0 International. 


\title{
Regards croisés sur la culture médiatique européenne
}

\author{
Kálai Sándor
}

Depuis déjà quelques décennies, on s'intéresse en Europe de l'Ouest aux phénomènes de la littérature populaire et, parallèlement, à ceux de la culture de masse (remplacer cette notion, particulièrement lourde de connotations idéologiques, par celle de culture médiatique était la proposition des chercheurs qui ont travaillé sur les produits massmédiatiques français/francophones [Lits 1999, Lits, 2006]). En ce qui concerne les études françaises/francophones, le rôle pionnier de l'Université de Limoges (avec une succession de colloques), la création, à partir de 1995, de la Coordination internationale des chercheurs en Littératures Populaires et Cultures Médiatiques, la fondation de la revue Belphégor, le projet commun d'EPOP (entre 2008 et 2010) des universités de Limoges, Bologne, Louvain-la-Neuve et Leiden indiquent, entre autres, l'implantation profonde de ces recherches. En 2011 s'est tenue à Limoges l'assemblée constitutive de l'Association internationale des chercheurs en Littératures Populaires et Cultures Médiatiques, fédératrice des études en ces domaines.

2 Les études qui ont porté sur des auteurs ou des œuvres oubliés ont également soulevé certains problèmes théoriques et méthodologiques, notamment celui de la délimitation temporelle des objets d'étude, ressaisis dans une perspective diachronique qui éclaire leurs filiations et interactions. Dans le processus dynamique d'émergence et d'expansion progressive d'une culture médiatique coalescente à la modernité, le XIX ${ }^{\mathrm{e}}$ siècle s'avère indubitablement décisif. Entre 1820 et 1850 un changement de paradigme a lieu en effet dans la culture européenne dont le vecteur est la presse (périodique et polyphonique): le paradigme argumentaire sera progressivement remplacé par le paradigme narratif (Vaillant). Les produits culturels possèdent désormais une fonction de médiation entre le monde et les lecteurs. Le succès phénoménal du roman-feuilleton de Sue, Les Mystères de Paris, déclenche une vague de traductions, d'imitations et d'adaptations, à tel point que le genre de mystère urbain peut être considéré comme l'un des premiers phénomènes de mondialisation en régime médiatique. Les 
publications du site Medias19.org (Kalifa-Thérenty et Thérenty) ont mis en évidence l'impact du roman de Sue et du genre sur la culture mondiale.

3 La culture de masse évolue, à cette époque, dans « un espace occidental, industrialisé et urbanisé, dans lequel les chemins de fer, la poste, le journal et l'école occupent une position centrale » (Mollier). Il faut insister sur la capacité de cette logique culturelle à toucher la quasi-totalité des habitants du pays concerné. Elle passe essentiellement par l'appropriation individuelle que suppose la lecture. En suivant les analyses de Jean-Yves Mollier, il faut distinguer quatre critères de l'émergence de cette logique culturelle :

4 - l'achèvement de l'instruction universelle (qui semble exclure l'Europe de Sud et de l'Est, sauf la Monarchie Austro-Hongroise) ;

5 - l'existence d'une presse de masse libre, diversifiée, touchant un public de plus en plus large ;

6 - le développement et la diffusion d'une culture pour tous : une industrie culturelle qui englobe le théâtre, le café-concert, le music-hall, le cirque (ou encore la rue, " comme lieu et symbole des nouvelles pratiques culturelles » (Kalifa, p.39, 2001), tous les spectacles et loisirs de la ville ; les Expositions universelles ou le sport-spectacle) ;

7 - la présence d'une littérature de grande diffusion, populaire par essence, transmédiatique.

8 Il faut insister sur le fait que le "modèle » théorique de la culture médiatique a été bâti en hypostasiant les formes historiques avérées en Europe de l'ouest (et surtout du Nord-Ouest) à compter des années 1830/40 puis en Amérique du Nord à partir des années 1880, mais qu'il ne s'applique que malaisément, au moins en termes de chronologie et de circulations multimédiatiques, à l'Europe de l'Est. Il s'avère important, d'une part, d'étudier l'émergence de la culture de masse en Europe de l'Est, de dresser les problèmes théoriques et méthodologiques qu'elle soulève et, d'autre part, de confronter ces résultats avec le « modèle » théorique de la culture médiatique.

Le colloque Réseaux, diffusion, acculturation - La naissance de la culture de masse en Europe, tenu en décembre 2014 à l'Université de Debrecen, organisé conjointement par l'Université de Debrecen, l'Université de Limoges et Queen's University of Belfast, a eu comme objectif de rassembler des chercheurs de l'Europe de l'Est et de l'Ouest, de confronter les investigations portant tant sur les phénomènes culturels orientaux qu'occidentaux et de jeter, ainsi, un regard nouveau sur la (naissance de la) culture médiatique européenne. Les axes principaux étaient les suivants :

10 1. Au lieu d'étudier, d'une manière traditionnelle, des auteurs et des œuvres (plus ou moins connus), il s'agissait de centrer l'attention sur l'activité culturelle en relation avec la diffusion et mettre ainsi en lumière des réseaux de diffusion ou des acteurs moins connus de l'activité culturelle (traducteurs, éditeurs ou distributeurs - comme Eichler, diffuseur des fascicules américains, Paul Winkler ou les frères Del Duca) dans le monde occidental (tant en Europe - de l'Ouest et de l'Est - que dans les Amériques). Il s'agissait également de tirer de l'oubli ceux qui ont travaillé dans les industries du spectacle ou dans la cinématographie. Une attention particulière était accordée aux activités culturelles qui regroupent les acteurs de plusieurs pays. On a cherché également à étudier les phénomènes de diffusion internationale, des cas de réception qui pourraient mettre en lumière des phénomènes d'acculturation, l'implantation d'un auteur, d'une œuvre, d'une pratique ou d'un phénomène et ses conséquences poétiques, culturelles ou sociales dans un autre paysage culturel. Cet axe résultait des 
conclusions collectives tirées lors du colloque de Louvain (octobre 2011) Les Racines populaires de la culture européenne (Delneste - Migozzi - Odaert - Tilleuil).

11 2. Il paraissait impératif de déclencher l'étude de la culture médiatique en Europe de l'Est. De quelle manière cette logique culturelle existe-t-elle dans les pays de l'Est ? À partir de quand? Quelles sont les conditions économiques, sociales et politiques de l'émergence de la culture de masse en Europe de l'Est ? Quelles sont les voies de passage de la culture populaire traditionnelle vers la culture de masse et quel rôle accorder à la communication écrite/imprimée? Est-ce qu'on peut identifier dans ces cultures le passage vers le paradigme narratif et, par conséquent, quelle est la situation de la presse et celle de la littérature, quelles sont les relations qui unissent ces deux sphères d'activités? Est-ce que les critères mentionnés ci-dessus sont remplis? Dans quelle mesure peut-on parler d'une culture urbaine ? Quelles sont les villes qui jouent un rôle important dans la production, la diffusion ou la réception des produits massmédiatiques? Quel est le statut de la langue, quelles sont les causes et les conséquences $\mathrm{du}$ plurilinguisme? Quels sont les acteurs de cette vie culturelle, quelles sont les œuvres fondatrices ou marquantes?

Dans cette perspective, la contribution de Jacques Migozzi, de portée générale, tire, d'une part, les conclusions des recherches menées jusqu'ici sur la littérature populaire et la culture médiatique, en mettant en avant les résultats du projet EPOP dont il était question ci-dessus. Cette synthèse permet d'aborder le problème de la périodisation, d'insister sur l'importance de la diffusion, de la traduction, de la sérialisation, de l'adaptation. Jacques Migozzi attire également l'attention sur l'occidentalocentrisme des théorisations et des périodisations des phénomènes de la culture médiatique d'où résulte une "tendance à surestimer dans notre saisie rétrospective de la culture populaire européenne la part "moderne", car promise à une expansion multimédiatique, au détriment du reste des produits et des usages qui seraient considérés comme seulement rémanents ou archaïques ». Tout semble porter à croire que l'émergence d'une culture médiatique est-européenne est sans doute tardive par rapport aux phénomènes ouest-européens, mais se caractérise aussi par des différences - et ce sont ces différences qui permettent, en retour, de modifier le regard jeté sur la culture médiatique occidentale.

Un premier ensemble d'articles est consacré à la situation hongroise. C'est par rapport aux études qui portent sur la culture médiatique française que Kálai Sándor propose un aperçu sur l'émergence de cette nouvelle logique culturelle en Hongrie, qui s'enracine essentiellement dans le contexte de la double monarchie austro-hongroise. Même s'il y a des ressemblances avec la culture médiatique ouest-européenne, il faut insister plutôt sur les différences, dues - entre autres - à des facteurs économiques (le retard de l'implantation du système capitaliste), sociaux (l'apparition tardive de la bourgeoisie, en grande partie d'origine étrangère, l'importance du multilinguisme dans un pays multiethnique) ou culturels. L'analyse permet de faire l'hypothèse de l'existence d'une "première phase " (1840-1920) de la culture médiatique, du moins pour le territoire hongrois, qui correspond, en gros, à la périodisation occidentale. L'article de l'ethnologue transylvain, Keszeg Vilmos, prend comme point de départ la théorie des niveaux de culture, et essaie de déterminer la place de la culture de masse et les points de jonction entre la culture de masse et la culture populaire/folklorique. L'article est structuré selon plusieurs axes: d'une part, il reconstruit le long processus au cours duquel la recherche scientifique a découvert et a identifié la culture populaire 
hongroise et ses diverses fonctions, et s'efforce ensuite de mettre en lumière les manières dont les récentes tendances du folklorisme et de la patrimonialisation ont essayé de 'revitaliser' cette culture. D'autre part, nous pouvons également avoir une idée sur la façon dont les différents médias de masse ont été 'domestiqués' par les usagers dans la vie de tous les jours, produisant une sorte de culture populaire. Troisièmement, l'article rassemble également, à partir de l'exemple de la Roumanie cette fois, les caractéristiques d'une culture de masse des régimes communistes/ socialistes. Le regard de l'auteur est celui de l'ethnologue, comme on l'a précisé, et son article est en même temps une sorte de résumé des résultats des recherches menées par l'école ethnologique de Cluj. L'article de Vincze Hanna Orsolya est consacré à l'ouvrage d'un important penseur hongrois de la deuxième moitié du XIX ${ }^{e}$ siècle, Eötvös József, intitulé L'influence des idées dominantes du XIXe siècle sur l'État. Il est lu ici dans la perspective de l'histoire des idées, en faisant un rapprochement entre le penseur hongrois et la tradition de la critique de l'aristocratie libérale, représentée par Tocqueville ou Burckhardt. C'est par cette voie que l'auteur arrive à l'examen de cette nouvelle configuration sociale et culturelle qui nous intéresse. Ces auteurs, précise-telle, voyaient tous les Lumières et la Révolution française comme le début de la modernité, apportant l'esprit commercial, le goût de l'uniformité, la domination de la classe moyenne, les affrontements entre les classes moyennes et inférieures. Leur critique des phénomènes modernes de massification et de commercialisation, et surtout de leurs conséquences politiques, n'a cependant pas rendu les aristocrates libéraux antimodernes. Leur insistance sur l'éducation était par exemple une caractéristique centrale de leur pensée humaniste moderne. L'article met aussi en lumière le fait que dans son ouvrage Eötvös a également introduit une nouvelle perspective : il a formulé une proposition visant à identifier les pratiques populaires de production de sens et à déchiffrer le sens que les gens attachent aux idées qui les rassemblent. Comme les gens qui se rassemblent autour des idées agissent avec émotion, ils sont guidés plutôt par des sentiments que par des notions articulées. Selon Eötvös, l'importance des émotions est une caractéristique de l'époque et doit être abordée si l'on veut comprendre ce à quoi les gens donnent sens.

Un deuxième groupe d'articles s'intéresse à différents aspects de la culture médiatique d'autres pays d'Europe de l'Est (l'Autriche, la Tchéquie, la Russie). L'article de Norbert Bachleitner étudie l'émergence de la presse populaire en Autriche, plus exactement à Vienne, phénomène qui n'a eu lieu qu'au moment de l'époque dite néo-absolutiste (1848-1860). Cette presse populaire intègre le roman-feuilleton : on peut donc constater que le genre se stabilise dans certaines aires culturelles d'Europe de l'Est avec très peu de retard par rapport à la France. Le feuilleton contribue à «la construction d'un espace mental collectif de la population». L'article établit aussi une corrélation des chiffres du tirage de la presse et de la stratification sociale de la population viennoise et, à partir de deux exemples, illustre la différence de sujet et d'écriture dans les deux sous-champs de la littérature autrichienne. L'article de Marcela Poučová, qui s'intéresse aux traductions tchèques de la littérature populaire française, donne, lui aussi, un aperçu sur l'évolution culturelle de la Tchéquie au XIX ${ }^{e}$ siècle. « Les nouvelles élites qui se créent à la fin du XVIII ${ }^{e}$ et pendant le XIX ${ }^{\mathrm{e}}$ siècles sortent des couches populaires et de la petite bourgeoisie. Les initiateurs du Renouveau tchèque, les intellectuels et les scientifiques d'origine tchèque sortent du système autrichien qui, sur son territoire, n'assure l'enseignement secondaire et universitaire qu'en allemand. » Ce processus du Renouveau s'achève au cours du siècle et, parallèlement, 
on voit l'émergence d'une culture médiatique sur une base plébéienne. Dans cette reconstruction, la traduction est un puissant moteur d'acculturation, permettant à la fois le rétablissement de la langue tchèque, la stimulation d'une production nationale, l'émergence des éditeurs, un public de plus en plus large et le changement du statut de traducteur, considéré comme un spécialiste. L'article de Kirill chekalov s'intéresse aux origines de la littérature de masse russe: selon lui, on peut les faire remonter à la deuxième moitié du $18^{\mathrm{e}}$ siècle, laquelle se caractérise par une importante activité de traduction de textes étrangers, majoritairement français, et par une production autochtone. Mais c'est surtout Thaddée Boulgarine qui peut être considéré comme le fondateur de la littérature de masse russe, à la fois directeur (son journal, L'Abeille $d u$ Nord, a été publié à partir de 1825) et auteur du premier bestseller russe, Ivan Vyjiguine (1829). Il s'agit d'un roman destiné essentiellement au public moyen, « c'est-à-dire aux marchands, aux bourgeois, aux petits nobles ", et qui suit une stratégie adaptée à cette situation: " un style vraiment moderne, dépourvu de l'archaïsation stylistique à la Narejny ; le sujet est assez captivant et varie les lieux (de Moscou à Venise, des steppes kirghizes à la Biélorussie, de Constantinople à Paris) et les milieux sociaux avec une grande aisance; il y a une alternance savamment dosée entre registres sérieux, émouvant, mélodramatique et comique ». Un important article est consacré, par Lampros Flitouris et Christos Dermentzopoulos, à l'étude du passage de la culture populaire à une culture de masse dans l'Europe du Sud-Est (la Grèce, la Turquie, l'Albanie, la Yougoslavie et la Bulgarie). Ce passage s'effectue de différentes manières selon les contextes nationaux. Dans le cas de la Grèce il s'observe déjà avant la guerre, même avant 1936, ensuite, après la guerre, les médias de masse (la radio, le cinéma et la musique enregistrée) permettent l'installation d'une culture de plus en plus américanisée. En Turquie, on peut observer des tendances similaires après les années 1940, mais ce pays se caractérise surtout par des clivages intérieurs. Le cas des autres pays balkaniques est compliqué par l'installation des régimes communistes: «La notion de "masses" resta à l'intérieur du cadre du réalisme socialiste et elle eut comme but essentiel de faire la propagande du régime pour les masses avec l'utilisation des canaux similaires à ceux que la culture-pop utilisait en Occident. » Un deuxième article, une étude de cas, est consacré à un aspect de la culture grecque: Nikos Filippaios s'intéresse aux magazines populaires grecs destinées aux enfants et aux jeunes dans les années 1950 et 1960. Selon l'auteur, il s'agit d'une époque qui est encore mal connue, faute d'études consacrées aux tendances culturelles. La présentation des magazines et l'analyse des personnages fictionnels récurrents sont accompagnées de considérations économiques et sociales, d'une mise en lumière du travail des artistes et des intermédiaires ainsi que de la réaction des intellectuels, de l'Église et des forces politiques. Les propos rejoignent la synthèse exposée dans l'article précédent, notamment en ce qui concerne les tendances à l'américanisation qu'on peut observer dans la Grèce de l'après-guerre.

Finalement, trois articles s'intéressent à diverses tendances qu'on peut observer dans certains pays de l'Europe occidentale, notamment en Espagne et en France. L'article d'Àngels Santa et Carme Figuerola s'intéresse, à travers l'exemple de Paul Féval et de George Sand, à l'écho du roman populaire français en Espagne. Tout comme l'article de Marcela Poučová, leur texte recense une importante liste de traductions. Cette étude sur les transferts culturels entre la France et l'Espagne, pays qui occupe une position subalterne par rapport à la France, met en lumière des processus d'acculturation à travers l'hispanisation des textes français et, par la présentation de la trajectoire des 
médiateurs culturels - traducteurs, illustrateurs ou éditeurs - le rôle que ces divers types de "passeurs " peuvent jouer. Le cas de George Sand est important aussi d'un autre point de vue: L'Hiver à Majorque, un récit qui ne donne pas une image flatteuse des habitants de l'île, contribue aussi à faire la renommée de l'île: littérature et marketing se rejoignent et cette rencontre offre aussi des pistes à explorer. L'article de Matthieu Letourneux se consacre à l'exploration de la première phase de l'américanisation, qui se manifeste, d'une manière exemplaire, dans l'activité de la maison d'édition d'Eichler. Celle-ci reprend des séries américaines avec des personnages, comme Nick Carter, qui sont déjà bien implantés dans la culture populaire américaine. L'article met en lumière les éléments de cette réussite : «c'est celle [la réussite] d'une des premières grandes maisons d'édition conçue comme une multinationale. C'est là l'étonnante modernité d'Eichler que de concevoir une véritable industrie européenne de l'édition, dans laquelle l'éditeur ne publie quasiment aucun texte original, mais se contente de traduire, d'un pays à l'autre, la matière qu'il rachète à d'autres. » En même temps, le succès réside aussi dans le fait que les personnages, autour de qui les séries sont centrées, s'inscrivent dans un imaginaire transmédiatique. L'article propose ainsi de procéder à des déplacements: au lieu de s'intéresser uniquement au texte (ce qu'on fait d'habitude), il faut l'inscrire plutôt dans «les dynamiques architextuelles et leur formulation dans les séries culturelles et médiatiques » ce qui permet d'accorder une autre place, dans les analyses, au problème de l'auctorialité. L'article de Paul Bleton, consacré à l'importation des fictions guerrières dans la littérature française, essaie de "valider l'intérêt spéculatif de la notion de "modèle national importé" au cœur du processus d'acculturation et sa relation à la coprésence de fictions françaises et de fictions traduites ». Pour étudier ce processus, qui est aussi une nouvelle vague d'américanisation, ressentie, dès les années 1950, non pas seulement par la paralittérature, mais aussi par la culture médiatique française, l'auteur évoque de possibles modèles allemand ou américain, mais on peut aussi identifier d'autres sources (russe, italienne) qui ne constituent pas pour autant de modèles. Contrairement aux attentes, l'influence américaine dans le genre de la fiction de guerre semble être faible.

16 Pour finir, on voudra esquisser ici quelques conclusions qui se sont dégagées de l'ensemble des articles, conclusions qui seront, en partie, reprises et approfondies dans la postface écrite par Jacques Migozzi.

17 «Regards croisés ", l'expression qu'on a adoptée comme titre, peut être donc comprise au moins de deux manières. Il peut s'agir, d'une part, de la multiplication possible (et souhaitée) des disciplines qui peuvent s'intéresser à l'étude de la culture médiatique : à part les travaux menés par des littéraires et des historiens (mais qui - ce dossier aussi en témoigne - élargissent leur terrain d'études et acceptent d'être confrontés à de nouveaux problèmes théoriques et méthodologiques), les analyses que des historiens des médias, des historiens des idées ou des ethnologues peuvent mener, contribuent à ouvrir les champs, à découvrir de nouveaux terrains, d'autres problématiques. L'expression signifie aussi, d'une manière plus concrète, le travail collectif mené par des chercheurs venant de différents pays d'Europe. La confrontation des analyses, d'où résulte par exemple l'idée de la rémanence des formes plus anciennes - théâtre, oralité, anciennes structures visuelles des villes - peut inciter à porter un regard nouveau sur la culture de masse occidentale, trop volontiers interprétée en termes de nouveauté (cf. l'article de Jacques Migozzi), ou à s'interroger sur les formes de résistance à la modernité massmédiatique européenne. L'ensemble des articles met également en 
lumière la coexistence de différentes temporalités dans l'évolution de la culture médiatique européenne et la nécessité d'étudier l'histoire longue de cette évolution (voir l'existence d'une littérature de grande consommation en Russie pendant le XVIII ${ }^{\mathrm{e}}$ siècle).

L'émergence d'une culture médiatique dans certains pays de l'Europe de l'Est contribue en même temps à la naissance d'une culture nationale. L'exemple de la Hongrie et de la Tchéquie témoigne par exemple du désir de se libérer de la domination autrichienne. Mais, en même temps, la constitution d'une telle culture ne peut pas se réaliser sans les transferts culturels (souvent des centres vers des périphéries). En ce qui concerne les évolutions plus tardives, plusieurs articles ont abordé le problème de ce qu'on appelle l'américanisation (processus de transfert entre l'Amérique et l'Europe). De même, il serait intéressant de voir en détail, du point de vue de l'évolution de la culture médiatique, les caractéristiques de la culture communiste-socialiste: dans quel sens peut-on la considérer comme une forme de la culture de masse?

Beaucoup d'articles se sont penchés également sur les phénomènes de diffusion - ce type d'étude justifie, et rend nécessaire, l'analyse de corpus plus grands. Elle invite en parallèle à porter l'attention sur les stratégies de différents types d'acteurs (écrivains, mais aussi traducteurs, adaptateurs, éditeurs...) dans un système littéraire et culturel en évolution permanente dans l'espace massmédiatique.

\section{BIBLIOGRAPHY}

Stéphanie Delneste, Jacques Migozzi, Olivier Odaert et Jean-Louis Tilleuil (dir), Les racines populaires de la culture européenne, Peter Lang, 2014.

Dominique Kalifa, La culture de masse en France, I. 1860-1930, Paris, La Découverte, 2001.

Dominique Kalifa et Marie-Eve Thérenty (dir), Les Mystères urbains au XIXe siècle : Circulations, transferts, appropriations, http://www.medias19.org/index.php?id=17039.

Marc Lits (coord.), Les Dossiers de l'ORM, n6: La culture médiatique aux XIX et XX ${ }^{e}$ siècles (novembre 1999).

Marc Lits, "La culture médiatique, ou la contamination de la culture par les médias ", in Culture de masse et culture médiatique en Europe et dans les Amériques (1860-1930), sous la direction de J.-Y. Mollier, J.-F. Sirinelli, F. Vallotton, Paris, PUF, 2006, 51-62.

Jean-Yves Mollier, «L'Émergence de la culture de masse dans le monde », in Culture de masse et culture médiatique en Europe et dans les Amériques (1860-1930), sous la direction de J.-Y. Mollier, J.-F. Sirinelli, F. Vallotton, Paris, PUF, 2006, 65-80.

Marie-Eve Thérenty (dir.), Les Mystères urbains au prisme de l'identité nationale, http:// www.medias19.org/index.php?id=13307.

Alain Vaillant, «Invention littéraire et culture médiatique au $19^{\mathrm{e}}$ siècle ", in Culture de masse et culture médiatique en Europe et dans les Amériques (1860-1930), sous la direction de J.-Y. Mollier, J.-F. Sirinelli, F. Vallotton, Paris, PUF, 2006, 11-22. 
INDEX

Keywords: Europe, Eastern Countries, Hungary, Greece, Czechoslovakia, Bulgaria, Austria, Spain, France, popular literature, popular culture, media culture

Mots-clés: Europe, Pays de l'Est, Roumanie, Hongrie, Grèce, Tchécoslovaquie, Bulgarie, Autriche, Espagne, France, Littérature populaire, culture populaire, culture médiatique 